\title{
FLUENCE DEPENDENT VARIATIONS OF BARRIER CHARGING AND GENERATION CURRENTS IN NEUTRON AND PROTON IRRADIATED Si PARTICLE DETECTORS
}

\author{
E. Gaubas, T. Čeponis, S. Sakalauskas, A. Uleckas, and A. Velička \\ Vilnius Universtity Institute of Applied Research, Saulètekio 9 bldg. 3, LT-10222 Vilnius, Lithuania \\ E-mail: eugenijus.gaubas@ff.vu.lt
}

Received 1 June 2011; revised 19 September 2011; accepted 21 September 2011

\begin{abstract}
The stability of the potential barrier is an essential characteristic in high energy particle detector operation under irradiation conditions. In this work a technique for barrier evaluation by linearly increasing voltage (BELIV) is presented, based on analysis of current transients measured at reverse biasing. The technique has been applied to diodes irradiated by neutrons and protons with fluences in the range of $10^{12}-10^{16} \mathrm{~cm}^{-2}$ in $1 \mathrm{MeV}$ neutron equivalent. Fluence and temperature dependent characteristics of the diode barrier capacitance as well as of generation current are discussed.
\end{abstract}

Keywords: charge extraction currents, junction barrier, generation current, radiation defects

PACS: $72.20 . J v, 71.55 . \mathrm{Eq}$

\section{Introduction}

The stability of the potential barrier in pin diodes under irradiation is an essential characteristic of semiconductor particle detectors [1]. In detectors heavily irradiated by high energy particles, the formation of extended defects inside the metallurgic junction area is very probable [2, 3]. As a consequence, the junction interface circuitry can be shortened by micro-plasma generation and other metallurgic junction damage related effects can occur. Commonly, barrier characteristics are examined by combined analysis of the capacitance-voltage $(C-V)$ and current-voltage $(I-V)$ characteristics measured on irradiated devices [4-6]. In this article a technique for barrier evaluation by linearly increasing voltage (BELIV) is presented, based on measurements of current transients at reverse biasing. This technique has been applied to an analysis of barrier quality of nonirradiated devices and of Si pad-detectors irradiated by reactor neutrons with fluences in the range of $10^{12}$ $3 \cdot 10^{16} \mathrm{~cm}^{-2}$ as well as by $8 \mathrm{MeV}$ protons.

\section{Samples and measurement circuitry}

A set of pin diodes with the CERN standard $\mathrm{p}^{+} \mathrm{nn}^{+}$ pad-detector structure (with dopant density in the nlayer of $N_{\mathrm{D}} \approx 2.3 \cdot 10^{12} \mathrm{~cm}^{-3}$ ) [1] were investigated.
These pin detectors were neutron irradiated with fluences in the range of $10^{12}-10^{16} \mathrm{~cm}^{-2}$ in $1 \mathrm{MeV}$ neutron equivalent, at the TRIGA reactor in Ljubljana. Other diodes were irradiated with $8 \mathrm{MeV}$ protons with a fluence of $2 \cdot 10^{14} \mathrm{~cm}^{-2}$ ( $1 \mathrm{MeV}$ neutron equivalent) using the particle accelerator of the Division of Materials Physics of the University of Helsinki. Measurements of the current transients were carried out in the temperature range between 150 and $300 \mathrm{~K}$. During the measurement, the diodes are placed on the cold finger of a vacuum cryostat, which is cooled by liquid nitrogen. The diode is connected to the measurement circuit with an appropriate electrode system. Connection is arranged to obtain the lowest system capacitance, and it is usually kept well below $1 \mathrm{pF}$ in our system. The initial step in the measurement procedure is to evaluate the background capacitance of the system when the measurement circuit is disconnected.

A sketch of the measurement circuitry used in the BELIV technique is shown in Fig. 1. Current transients are registered using the $50 \Omega$ load input of an Agilent DSO6102A oscilloscope. Additionally, the measurement circuitry contains the adjustable output of a generator of linearly increasing voltage (GLIV) and the diode under investigation, connected in series. The transient currents are measured in the range from tens of $\mu \mathrm{A}$ to tens of $\mathrm{mA}$ using GLIV pulses with durations in the 
range between $100 \mathrm{~ns}$ and $10 \mathrm{~ms}$, while measurements are performed without any additional current amplifier. Junctions of various material, area, and doping can be investigated. The sensitivity of the barrier capacitance current measurement can be varied by changing the ramp of the LIV pulses. In addition, it can be increased by using a current amplifier, when necessary. An averaging of 10-100 transients is usually performed to reduce statistical noise. Linearity of the GLIV signal is essential for the implementation of the BELIV technique. Therefore, the LIV signal and its derivative, measured simultaneously using the second channel of the oscilloscope, are always recorded. The measurement system is computer controlled.

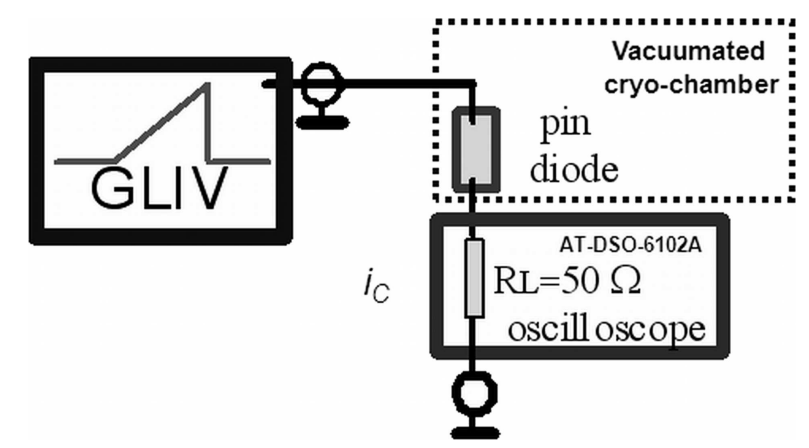

Fig. 1. Sketch of the measurement set-up for the implementation of the BELIV technique. GLIV is a generator of linearly increasing voltage.

\section{Principles of the extraction of parameters}

The barrier evaluation by linearly increasing voltage (BELIV) technique is founded on analysis of current transients measured for reverse and forward biased junction. For reverse biased diodes, the BELIV technique is based on the analysis of barrier capacitance $C_{\mathrm{b}}$ changes with a linearly increasing voltage pulse $U=A t$. The $C_{\mathrm{b}}$ dependence on voltage and thereby on time $t$ can be described using the depletion approximation [7] in the analysis of charge extraction transients in the trap-free material. This approximation leads to the simple relation $C_{\mathrm{b}}=C_{\mathrm{b} 0}\left(1+U / U_{\mathrm{bi}}\right)^{-1 / 2}$ for an abrupt $\mathrm{p}^{+}-\mathrm{n}$ junction in the pin diode, where the barrier capacitance $C_{\mathrm{b} 0}$ for the non-biased diode of area $S$ is given by $C_{\mathrm{b} 0}=\varepsilon \varepsilon_{0} S / w_{0}=\left[\varepsilon \varepsilon_{0} S^{2} \text { e } N_{\mathrm{D}} /\left(2 U_{\mathrm{bi}}\right)\right]^{1 / 2}$. Here $\varepsilon_{0}$ is the vacuum dielectric constant, $\varepsilon$ the material permittivity, $e$ the elementary charge, $U_{\mathrm{bi}}$ the built-in potential barrier, $w_{0}=\left[2 \varepsilon \varepsilon_{0} U_{\mathrm{bi}} /\left(e N_{\mathrm{D}}\right)\right]^{1 / 2}$ the width of depletion for non-biased junction, and $A=U_{\mathrm{P}} / \tau_{\mathrm{PL}}$ the ramp of the LIV pulse with amplitude $U_{\mathrm{P}}$ and of duration $\tau_{\mathrm{PL}}$.
The time dependent changes of the charge $q=$ $C_{\mathrm{b}} U$ within the junction determine the current transient $i_{C}(t)$ :

$$
\begin{aligned}
& i_{C}(t)=\frac{\mathrm{d} q}{\mathrm{~d} t}=\frac{\partial U}{\partial t}\left(C_{\mathrm{b}}+U \frac{\partial C_{\mathrm{b}}}{\partial U}\right)=\frac{\partial U}{\partial t} C_{\mathrm{b} 0} \\
& \times \frac{1+U_{C}(t) /\left(2 U_{\mathrm{bi}}\right)}{\left[1+U_{C}(t) / U_{\mathrm{bi}}\right]^{3 / 2}} \cong A C_{\mathrm{b} 0} \frac{1+A t /\left(2 U_{\mathrm{bi}}\right)}{\left[1+A t / U_{\mathrm{bi}}\right]^{3 / 2}} .
\end{aligned}
$$

This transient contains an initial $(t=0)$ step $A C_{\mathrm{b} 0}$ due to displacement current and a decreasing component governed by charge extraction. The latter component gives an additional relation to extract $U_{\mathrm{bi}}$ by taking the ratio $r_{m}=i_{C}(0) / i_{C}\left(t_{m}\right) \geq 1$ at a fixed time $t_{m}$. Subsequently the value of $N_{\mathrm{D}}$ (or $N_{\text {Def }}=N_{\mathrm{D}}-N_{\mathrm{A}}$, where $N_{\text {Def }}$ is the effective doping density and $N_{\mathrm{A}}$ is the density of compensation centres in n-type material) is evaluated by substituting the extracted $U_{\mathrm{bi}}$ in the initial current expression $i_{C}(0)=A C_{\mathrm{b} 0}$. To extract the barrier parameters more precisely, the above procedure can be applied after the diffusion current is evaluated. The diffusion current $i_{\text {diff }}[8,9]$ stabilises rapidly with reverse bias voltage. The steady value of $i_{\text {diff }}$ can be ignored in comparison with $i_{C}(t)$ for properly fabricated (containing low trap density) pin diodes in a realistic range of LIV pulse durations. However, the diffusion current can be important in the initial stage of the transients. In reality, a delay appears due to serial processes of dielectric relaxation within the boundary of the quasi-neutral range of the non-depleted $n$ layer, drift and diffusion of carriers to complete the circuit. The resulting $\tau_{R C}$ modifies crucially the initial current step $i_{C}(0)$ by decreasing its amplitude $i_{C}(0)$ by a factor $\exp \left(-t / \tau_{R C}\right)$. The modified current $i_{C \mathrm{M}}(t)$ transient, caused by $\tau_{R C}$, is described using the Green's function method [10, 11] which leads to a convolution integral (with $\tau_{R C}=m R C$ dependent on the precision required, where $m$ is a multiplier for taking into consideration further iterations in changes of the signal due to $\mathrm{RC}$ transient processes)

$$
i_{C \mathrm{M}}(t)=\frac{1}{\tau_{R C}} \int_{0}^{t} i_{C}(x) \exp \left[-(t-x) / \tau_{R C}\right] \mathrm{d} x .
$$

The qualitative changes of the transients, simulated using Eqs. (1) and (2), are illustrated in Fig. 2(a). It is clearly seen that both a delayed ramp and a shift of the $i_{C \mathrm{M}}(t)$ peak appear. Fitting of the experimental transient $i_{C \mathrm{M}}(t)$ by Eq. (2) with $\tau_{R C}$ as a fitting parameter, allows the extraction of $U_{\mathrm{bi}}$ and $C_{\mathrm{b} 0}$. Reduction of $A$ decreases $i_{C}(t)$ (especially $i_{C}(0)=A C_{\mathrm{b} 0}$ ) 

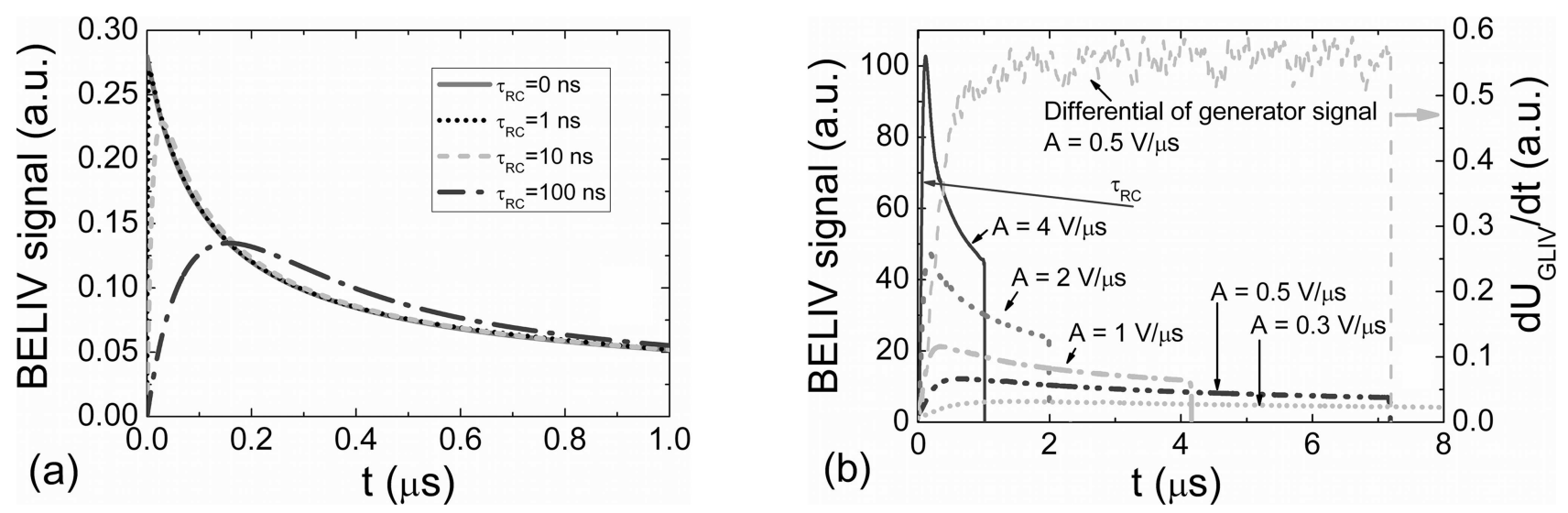

Fig. 2. (a) Simulated charge extraction current transients without (solid) and with (dash) integration circuit due to $R C$ of $\tau_{R C}=0,1,10$, and $100 \mathrm{~ns}$, respectively. (b) Charge extraction current transients measured in a pin diode with reverse $(U)$ polarity LIV pulses of varied ramp $A$.

and increases the initial delay. Real GLIV signals contain an intrinsic ramp (rising) delay of about $2-10 \%$ relative to the LIV pulse duration, therefore short LIV pulses are preferable in BELIV measurements. The transients measured in commercial encapsulated diodes and non-irradiated pad-detectors agree well with the BELIV model of charge extraction current transients, Fig. 2(b).

In materials containing a considerable density of deep traps, modification of the $i_{C \mathrm{M}}(t)$ transient by $\tau_{R C}$ within the initial part appears to be more complicated when $\tau_{R C}$ is governed by carrier capture/release processes [7]. For non-encapsulated diode structures, the initial change of $i_{C \mathrm{M}}(t \approx 0)$ can be suppressed by steady-state IR illumination. Additionally, the $i_{C \mathrm{M}}(t \approx 0)$ can be manipulated by imposing a dc voltage pedestal of varied polarity on the LIV pulse. Using both IR and dc forward bias steady-state priming in pulsed barrier capacitance measurements, the traps are primarily filled in between the LIV pulses, owing to carriers introduced by light (IR) or external voltage (dc $U_{F}$ ) source.

Radiation induced traps are responsible for a generation current [9] within the depletion region. This current $i_{\mathrm{g}}(t)=e n_{i} S w_{0}\left(1+A t / U_{\mathrm{bi}}\right)^{1 / 2} / \tau_{\mathrm{g}}$ increases with voltage $U(t)$ and can exceed the barrier charging current in the rearward range of the pulsed transient when the carrier generation lifetime $\tau_{\mathrm{g}}$ is rather short. In a more detailed analysis of the impact of traps [7] on barrier capacitance changes with time, traps located below the mid-gap are assumed to be the compensation centres which modify the effective doping density (in the expressions for $w_{0}$ and $C_{\mathrm{b} 0}$ ). Deep centres, located in the upper-half of the band-gap, are able to respond rapidly by majority carrier capture/emission and to modify the space charge in the time scale of the dielectric relaxation.

The total reverse current transient is described by the $\operatorname{sum} i_{\mathrm{R}}(t)=i_{C}(t)+i_{\text {diff }}(t)+i_{\mathrm{g}}(t)$ :

$$
\begin{aligned}
i_{\mathrm{R}}(t)= & A C_{\mathrm{b} 0} \frac{1+U_{C}(t) /\left(2 U_{\mathrm{bi}}\right)}{\left[1+U_{C}(t) / U_{\mathrm{bi}}\right]^{3 / 2}} \\
& +i_{\mathrm{diff} \infty}\left[1-\exp \left(-\frac{-e U_{C}(t)}{k_{\mathrm{B}} T}\right)\right] \\
& +\frac{e n_{i} S w_{0}}{\tau_{\mathrm{g}}}\left(1+\frac{U_{C}(t)}{U_{\mathrm{bi}}}\right)^{1 / 2} .
\end{aligned}
$$

The decreasing charge extraction and increasing generation current variation with LIV pulse time (voltage) implies the existence of a current minimum within the transient. The time instant $t_{\mathrm{e}}$ for this extremum can be found by using the condition $\partial i_{\mathrm{R}} /\left.\partial t\right|_{t_{\mathrm{e}}}=0$. This leads (assuming $\partial i_{\text {diff }}(t) / \partial t=0$ for $t_{\mathrm{e}} \gg k_{\mathrm{B}} T /(e A)$ ) to a relation for an extremum time instant $t_{\mathrm{e}}$ and to a minimal total current value, expressed by initial values of barrier charging and generation currents $i_{C}(0)$ and $i_{\mathrm{g}}(0)$ as

$$
\begin{aligned}
t_{\mathrm{e}}= & {\left[\frac{i_{C}(0)}{4}-i_{\mathrm{g}}(0)+\sqrt{\left(\frac{i_{C}(0)}{4}\right)^{2}+\frac{3}{2} i_{C}(0) i_{\mathrm{g}}(0)}\right] } \\
& \times \frac{U_{\mathrm{bi}}}{A i_{\mathrm{g}}(0)} .
\end{aligned}
$$

The initial current component $\left(i_{\mathrm{R}}(t) \approx i_{C}(t)+\right.$ $i_{\text {diff }}(t) \gg i_{\mathrm{g}}(0)$ for $\left.t \ll t_{\mathrm{e}}\right)$ can be used to determine the barrier $U_{\text {bi }}$ using Eqs. (1) and (2). Subsequently, the carrier generation lifetime can be determined using Eq. (4). For a reverse bias LIV, the main voltage drop appears on the diode, and errors due to voltage distri- 
bution between diode and load resistor $R_{\mathrm{L}}$ can be ignored for small leakage currents, for small LIV voltages, and for diodes with rather small barrier capacitance. The value of the GLIV voltage should be replaced by $U(t)=A t-R_{\mathrm{L}} i_{\mathrm{R}}(t)$ and voltage sharing between load resistor and diode with consequent delay in $U_{C}(t)$ must be used during the second iteration of modelling. In a more rigorous approach, nonlinear differential equations and transcendental equations should be solved to simulate the variations of the BELIV transients. Injection current transients and their analysis become more complicated for forward biasing of a diode. The latter analysis will be published elsewhere [12].

\section{Variation of characteristics with irradiation fluence and temperature}

The variation of the charge extraction transients in $\mathrm{Si}$ pin diodes with neutron and proton irradiation fluence $\Phi$ and with temperature are illustrated in Fig. 3. It is clearly observed (Fig. 3(a)), that for relatively small fluences the charge extraction current dominates. Increasing the neutron irradiation fluence leads to a reduction of the barrier capacitance and to an increase of the space charge generation (leakage) currents. A similar dependence of the BELIV transients on fluence have been observed for neutron and proton irradiation (Fig. 3(a)).

For diodes irradiated with fluences of $10^{14} \mathrm{n} \mathrm{cm}^{-2}$ and above, the generation current becomes the prevailing component within the later stage of the current pulse. Carrier capture processes, with inherent $R C\left(R \sim 1 /\left(e n_{0} \mu_{e}\right)\right.$ and $\left.n_{0} \sim 1 / \Phi\right)$, modify the initial component of the transient, as well. The interplay of carrier capture/space charge generation processes within the depleted and transition layers is analysed in detail in [7]. Priming of the steady-state trap filling can be implemented by a small forward dc bias (using injection of minority carriers and consequent majority carrier supply into the neutral region from the external electrode, due to narrowing of the depletion width) between the LIV pulses (Fig. 3(b)). As a consequence, the peak of the barrier charging current pulse shifts (shown in Fig. 3(b) by symbols) towards the beginning of the LIV pulse. In the case of dc forward voltage bias, an increase of the barrier charging current is observed when minority carrier traps are filled and $N_{\text {Def }}$ is consequently increased thereby modifying the depletion width. Then, a delay $\Delta \tau_{R C}$ of the peak of current transient (Fig. 3(b)), determined by changes of the serial resistance of diode base, can be measured, as the shape of current transient is invariable. Using continuous wave (cw) bias illumination (BI) with varying intensity and of proper spectral range, both minority and majority (Fig. 3(c)) carrier traps can be saturated in diodes irradiated up to moderate fluences of $\leq 10^{14} \mathrm{n} \mathrm{cm}^{-2}$. In this case, an increase of the barrier charging current peak with bias illumination intensity is also observed. However, this barrier charging current enhancement - which indicates an increase (restoration) of the doping density - is followed by an increase of the generation current (Fig. 3(c)). To highlight this increase of generation current component, BELIV transients were normalized in Fig. 3(c) to the barrier charging current peak value for each transient. This enables one to extract the carrier generation lifetime by separating the peculiar point $t_{\mathrm{e}}$ in the transients in Fig. 3(c).

The impact of carrier generation centres can be also suppressed by varying the temperature. The reduction of the generation current with temperature is illustrated in Fig. 3(d). Carrier capture/emission lifetimes can be increased by reducing temperature and by varying either intensity of the $\mathrm{cw}$ BI or dc forward voltage pedestal. However, it is possible only for diodes irradiated with fluences $\leq 10^{14} \mathrm{n} \mathrm{cm}^{-2}$. For diodes irradiated with fluences $>10^{15} \mathrm{~cm}^{-2}$, due to which the carrier recombination lifetimes are shortened to a few ns or hundreds of picoseconds [13], the barrier capacitance values decrease approaching that of the geometrical capacitance. For reduced temperatures (to about $170 \mathrm{~K})$, BELIV transients measured on diodes irradiated with a neutron fluence of $10^{16} \mathrm{n} \mathrm{cm}^{-2}$ (Fig. 3(d)) have the expected shape for a capacitor. Additionally, the extracted capacitance value agrees well with that estimated for the geometrical capacitance of the investigated diodes. This result indicates full depletion of a diode for LIV voltage values close to zero, e. g. for $U_{C}(t=50 \mathrm{~ns}) \leq 0.3 \mathrm{~V}$ (Fig. 3(d)), one obtains $C_{\mathrm{b} 0} \approx$ $8.7 \mathrm{pF}$ for a diode irradiated with $10^{16} \mathrm{n} \mathrm{cm}^{-2}$ fluence and cooled to $170 \mathrm{~K}$.

The analysis of the measured BELIV transient changes, shown in Fig. 3, provides qualitative information about the fluence and temperature dependent variations of the junction parameters and their possible modifications by external conditioning (dc voltage/IR illumination priming and temperature). To extract the barrier parameters more precisely, fitting of the measured transients by simulated ones is essential. There are several approaches to implementation of fitting procedures dependent on the observed initial delays relative to the LIV pulse, the regularity of GLIV pulses, the values of applied LIV voltages, the values of barrier 


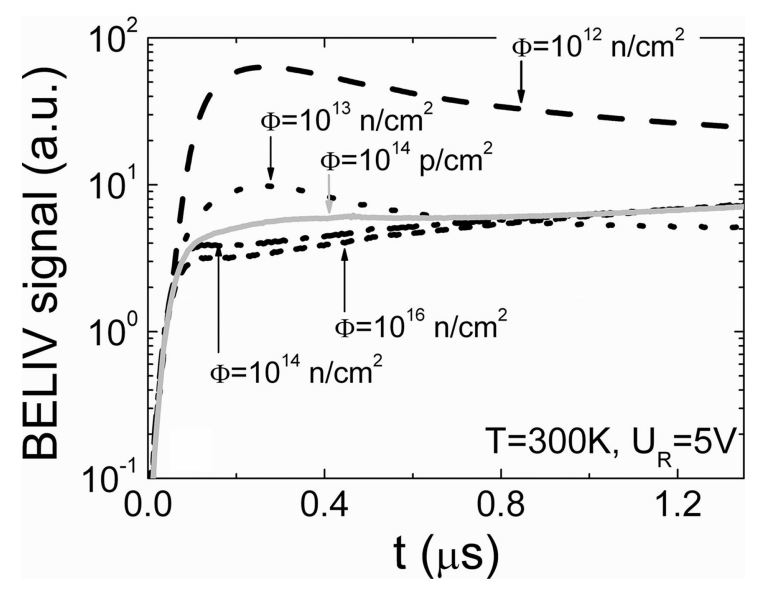

(a)

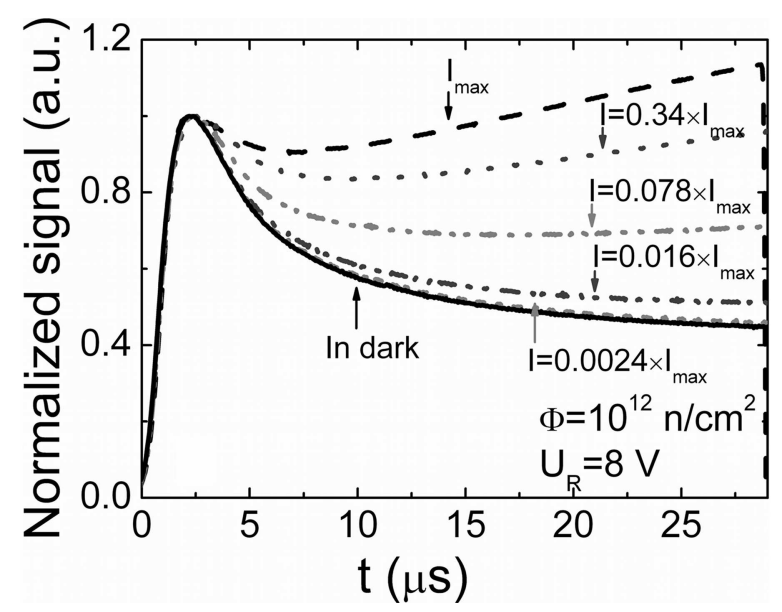

(c)

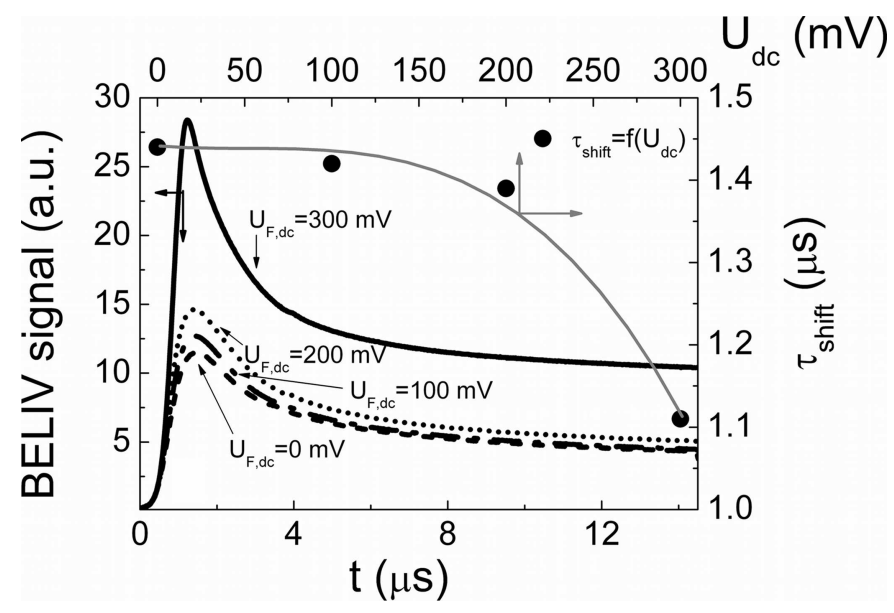

(b)

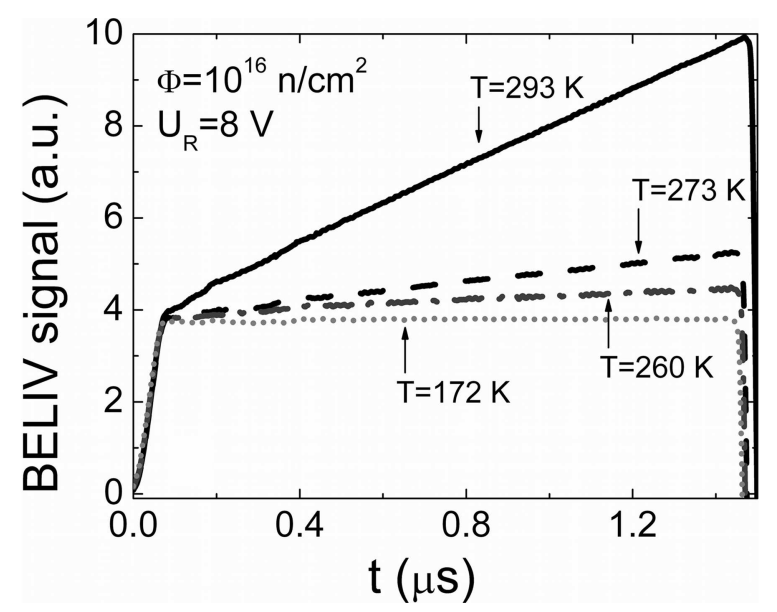

(d)

Fig. 3. (a) Fluence dependent variations of BELIV transients in neutron (black curves) and proton (grey) irradiated diodes. (b) Dc voltage bias dependent charge extraction transients. (c) Modification of BELIV transients by varying the intensity of cw illumination. (d) Temperature dependent variations of BELIV transients in heavily irradiated $\left(\phi=10^{16} \mathrm{n} \mathrm{cm}^{-2}\right)$ Si diode.

capacitance (area of junction), and the prevailing processes within the junction (impact of space charge generation current, rapid carrier capture/emission by fast deep centres in the upper half of band-gap, etc.). The influence of these factors can be estimated from a qualitative analysis of the experimental BELIV transients (as discussed for Fig. 3). For short regular GLIV pulses of voltage $<10 \mathrm{~V}$ applied to diodes with barrier capacitance $<300 \mathrm{pF}$, the time dependent nonlinear voltage sharing between the components of the $R C$ circuit can be ignored during the first iteration of the fitting procedure. Then the analytical approximation (Eqs. (1)-(4)) is applicable in the fitting procedure. A sketch of the fitting procedure applied to BELIV transients measured at $295 \mathrm{~K}$ temperature on a diode irradiated with $10^{13} \mathrm{~cm}^{-2}$ neutron fluence is presented in Fig. 4. Given the impact of traps in space charge generation and diffusion currents implied from the primary qualitative analysis, in order to have a closed system of equations, the set of LIV voltage varied BELIV transients (Fig. 4(a)) are simultaneously fitted, keeping a fixed set of adjustable parameters $\left(N_{\mathrm{D}}, \tau_{\mathrm{g}}\right.$, and $\left.i_{\text {diff } \infty}\right)$. The fitting procedure is finished when the best fit of required precision (controlled by NLS, the non-linear least squares algorithm) is obtained for all the transients included (in Fig. 4(a)), and values of $N_{\mathrm{D}}, \tau_{\mathrm{g}}$, and $i_{\text {diff } \infty}$ are simultaneously extracted.

The input of the required set of independent equations (transients) and parameters in the optimization of the fitting task is determined by the primary fitting step. This procedure is illustrated in Fig. 4(b). The experimental transient can be successfully fitted with minimal current components and their parameters analysed. In the discussed fitting procedure, the barrier charging current, the generation current, and the diffusion current components (shown by the broken curves in 

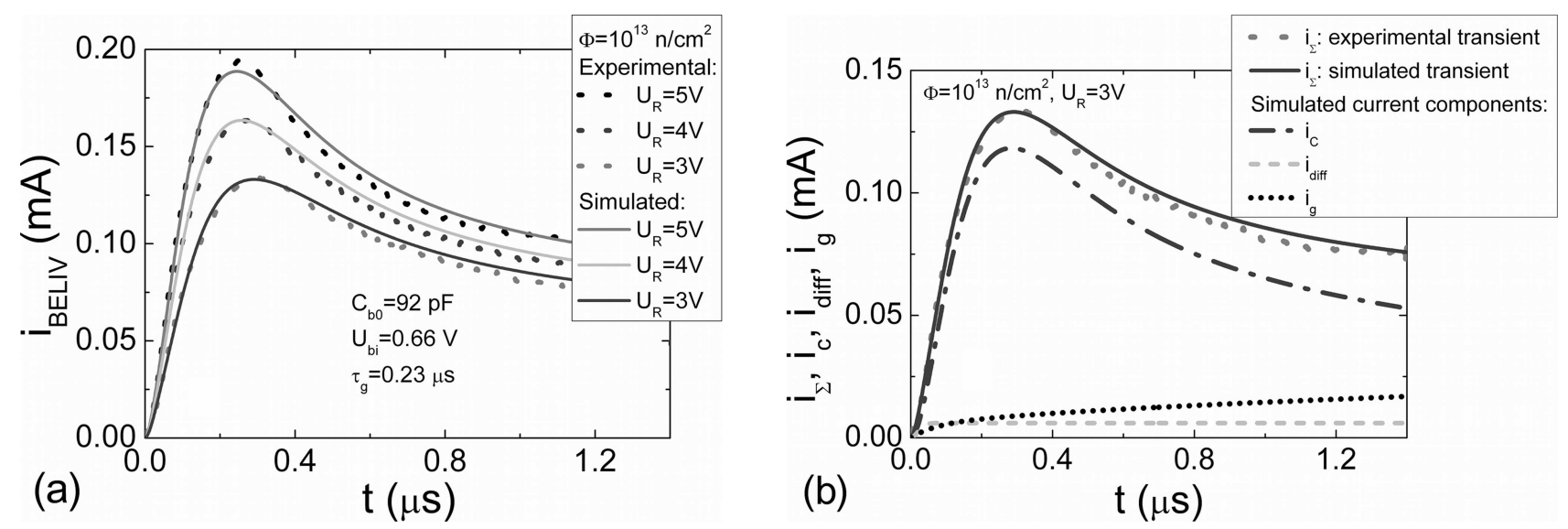

Fig. 4. (a) A set of barrier capacitance charging current transients (dots), measured by the BELIV technique at different ( 3,4 , and 5 V) LIV voltages on a Si diode irradiated with neutron fluence of $10^{13} \mathrm{~cm}^{-2}$, simultaneously fitted by simulated ones (using Eqs. (1) and (3)) (lines), keeping a fixed set of adjustable parameters: $N_{\mathrm{D}}=1.05 \cdot 10^{12} \mathrm{~cm}^{-3}, \tau_{\mathrm{g}}=0.23 \mu \mathrm{s}$, and $i_{\text {diff } \infty}=6 \mu \mathrm{A}$. (b) Comparison of the barrier capacitance charging current transient (dots) measured for a 3 V LIV pulse with the simulated total barrier current (solid line), composed of the barrier capacitance charging current (dash-dot), of the diffusion current (short-dash), and of the generation (short-dot) current.

Fig. 4(b)) should be involved. It is assumed that parameters, such as $U_{\mathrm{bi}}, C_{\mathrm{b} 0}$, and $w_{0}$, are defined by an adjustable value of $N_{\mathrm{D}}$ for $i_{C}(t)$ simulations using Eq. (3). There a simple solution of the linear RC circuit for a LIV pulse is used, leading to a time-dependent voltage drop on the barrier under test, expressed as $U_{C}(t)=$ $A\{t-R C[1-\exp (-t /(R C))]\}$. It is worth noting that for a pure capacitor and for time instants $t \gg R C$ (after the initial rise), the voltage on the load resistor $U_{R}(t)=\left.A C R\{1-\exp [-t /(R C)]\}\right|_{t \gg R C} \cong A R C$ is invariant, due to the exact compensation of voltage changes on the capacitor and the resistor (at every time instant). Thus, for a LIV pulse $U_{\mathrm{P}}(t)=A t$, the RC circuit with linear elements of $R$ and $C$ exhibits a steplike transient shape with a flat vertex. This can be an indication (Fig. 3(d)) of degradation of the diode barrier, when the material of the diode base mutates from the semiconducting state to an insulating one, due to heavy irradiation. The parameter $R C$ is defined by the characteristics of the load resistor and of the diode under test. The transient for the fixed LIV pulse is then simulated to fit the experimental transient of the total current shown in Fig. 4(b) and to evaluate the primary set of $N_{\mathrm{D}}, \tau_{\mathrm{g}}$, and $i_{\text {diff } \infty}$ values.

The extracted set of parameters reveals a reduction of $N_{\mathrm{D}}$ to $1.05 \cdot 10^{12} \mathrm{~cm}^{-3}$ (compared to the value for a non-irradiated diode, $N_{\mathrm{D}}=2.3 \cdot 10^{12} \mathrm{~cm}^{-3}$ ), an increase of generation and diffusion currents (with $\tau_{\mathrm{g}}=$ $0.23 \mu \mathrm{s}$ and $i_{\text {diff } \infty}=6 \mu \mathrm{A}$ ), after neutron irradiation with a fluence of $10^{13} \mathrm{~cm}^{-2}$. This fitting approach works even better for diodes irradiated with lower fluences, whereby larger values of $N_{\mathrm{D}}$ are obtained. For more complicated situations (e.g. the appearance of a series resistance due to a decrease of $n_{0}$ ), transients measured at reverse LIV pulse are simultaneously examined with those registered with forward bias LIV pulses within the BELIV technique.

\section{Summary}

In summary, the BELIV technique presented is a tool for the fast evaluation of barrier parameters in radiation detector pin structures. It enables one to examine changes of $\tau_{\mathrm{g}}$ and $N_{\mathrm{D}}$ parameters with temperature and fluence. Variations of the extracted parameters $\tau_{\mathrm{g}}, U_{\mathrm{bi}}$, and $N_{\mathrm{D}}$ as functions of irradiation fluence are in good agreement with the results of $C-V, I-V$, and MW-PCT (microwave probed photoconductivity transients) characterization of the same samples. The fluence dependent variations of BELIV transients examined indicate a reduction of the barrier capacitance, which approaches that of the geometrical capacitance when the neutron irradiation fluence is increased to $10^{16} \mathrm{n} \mathrm{cm}^{-2}$.

\section{Acknowledgements}

G. Kramberger is appreciated for the neutron irradiations at TRIGA reactor. E. Tuominen and J. Raisanen are acknowledged for providing detectors and proton irradiations. Authors thank J. Vaitkus for discussions. K. Smith and J. Vanhellemont are appreciated for help with editing the manuscript and valuable suggestions. This work was supported by the Lithuanian Research Council Grant MIP-11018/-54. 


\section{References}

[1] http://www.cern.ch/rd50/.

[2] M. Huhtinen, Simulation of nonionising energy loss and defect formation in silicon, Nucl. Instrum. Methods A 491, 194-215 (2002).

[3] P.F. Ermolov, D.E. Karmanov, A.K. Leflat, V.M. Manankov, M.M. Merkin, and E.K. Shabalina, Neutronirradiation-induced effects caused by divacancy clusters with a tetravacancy core in float-zone silicon, Semiconductors 36, 1114-1122 (2002).

[4] A.F. Yaremchuk, A contribution to the theory of the $C$ $V$ technique for the evaluation of carrier-concentration profiles in semiconductors, Appl. Phys. A 80, 881-883 (2005).

[5] M. McPherson, Capacitive effects in neutron-irradiated silicon diodes, Nucl. Instrum. Methods A 488, 100-109 (2002).

[6] D. Campbell, A. Chilingarov, and T. Sloan, Frequency and temperature dependence of the depletion voltage from CV measurements for irradiated Si detectors, Nucl. Instrum. Methods A 492, 402-410 (2002).
[7] P. Blood and J.W. Orton, The Electrical Characterization of Semiconductors: Majority Carriers and Electron States (Academic Press, London-San Diego-New York, 1992).

[8] S.M. Sze, Physics of Semiconductor Devices, 2nd ed. (John Wiley and Sons, New York, 1981).

[9] B.Y. Baliga, Power Semiconductor Devices (PWS Publishing Company, Boston, 1995).

[10] P.M. Morse and H. Feshbach, Methods of Theoretical Physics, Part I (McGraw-Hill Book Company, New York, 1953).

[11] D.G. Duffy, Green's Functions with Applications (Chapman \& Hall/CRC, New York, 2001).

[12] E. Gaubas, T. Ceponis, V. Kalendra, J. Kusakovskii, and A. Uleckas, Barrier evaluation by linearly increasing voltage technique applied to Si solar cells and irradiated pin diodes, ISRN Mater. Sci. [in press].

[13] E. Gaubas, A. Uleckas, and J. Vaitkus, Spectroscopy of neutron irradiation induced deep levels in silicon by microwave probed photoconductivity transients, Nucl. Instrum. Methods A 607, 92-94 (2009).

\title{
BARJERINĖS TALPOS IR GENERACINĖS SROVE்S KITIMAI NEUTRONAIS IR PROTONAIS APŠVITINTUOSE Si DALELIŲ DETEKTORIUOSE
}

\author{
E. Gaubas, T. Čeponis, S. Sakalauskas, A. Uleckas, A. Velička \\ Vilniaus universiteto Taikomuju mokslu institutas, Vilnius, Lietuva
}

\section{Santrauka}

Aukštuju energijų spinduliuotės detektorių sandūrų potencinio barjero stabilumas kintant apšvitos įtèkiui yra viena esminių tokiu detektorių funkcinių charakteristikų. Šiame darbe yra pateikta barjero įvertinimo tiesiškai didèjančios įtampos impulsinè metodika (BELIV) pagrįsta srovių kinetikų analize. Šis metodas buvo pritai- kytas Si dalelių detektorių, apšvitintų skvarbiaisiais protonais bei $1 \mathrm{MeV}$ energijos ekvivalento neutronais $10^{12}-10^{16} \mathrm{~cm}^{-2}$ itèkių srityje, barjerinès talpos bei generacinès srovès kaitos įvertinimams. Aptarta barjerinès talpos ir generacinès srovès charakteristiku priklausomybẻ nuo apšvitos įtėkio, temperatūros, nuostovaus pašvietimo. 